\title{
Creative Expression: Effectiveness of a Weekly Craft Group with Women Who Have Experienced Trauma
}

\author{
Linda Garner \\ Department of Nursing, Southeast Missouri State University, Cape Girardeau, USA \\ Email: Igarner@semo.edu
}

Received 18 January 2015; accepted 1 February 2015; published 4 February 2015

Copyright (C) 2015 by author and Scientific Research Publishing Inc.

This work is licensed under the Creative Commons Attribution International License (CC BY). http://creativecommons.org/licenses/by/4.0/

(c) (i) Open Access

\section{Abstract}

Creativity interventions have been shown to positively influence psychological and emotional health indicators. Nurses can play an important role in the development and implementation of interventions designed to counter the longer-term emotional and psychological consequences of trauma. The purpose of this study was to explore how participation in a nurse-facilitated weekly craft group may influence anxiety, depression, self-esteem, and self-confidence among women who have emotional and physical experienced trauma. A pre/post visual analog scale was used during a 7-week intervention to measure changes in anxiety, depression, stress, self-esteem and self-confidence among a convenience sample of adult female trauma survivors $(n=33)$. A paired sample $t$ test was used to evaluate the intervention with significance set at $p=0.05$. Participant observation and field notes were used for qualitative data generation. Significant reductions were noted in anxiety, depression, and stress along with significant increases in self-esteem and selfconfidence. Cohen's d statistic indicated a large effect size for anxiety (0.72) and stress (0.69). Moderate effect size was determined for self-confidence (0.36), depression (0.41), and self-esteem (0.52). Emergent qualitative themes included: creative expression improved confidence to sooth the self, safe spaces fostered creativity, a sense of accomplishment was stimulated through creative activities, and creative expression groups provided opportunities for positive affirmation. Offered as a complementary intervention, nurse-facilitated creative expression groups can support continued healing long after traditional support services have been exhausted. It is important for nurses to pursue a greater understanding of the art of nursing and the important contribution of creativity when used as a nursing intervention with trauma survivors.

\section{Keywords}

Creative Expression, Crafting, Therapeutic Groups, Trauma Survivors, Art of Nursing 


\section{Introduction}

Women who experience emotional and physical trauma often undergo significant alterations in health status [1]. The effects of trauma can linger for long periods of time. Even women who engage in well-designed and intensive support services remain at risk to experience intermittent or prolonged periods of anxiety, depression, and stress long after exposure to the trauma has ended [2] [3]. Interventions that make use of creativity have been shown to positively influence psychological and emotional health indicators [4]-[6]. Creativity balanced with the structure of a weekly group experience can influence the healing process for traumatized women who feel their lives are chaotic, fragmented and lacking in power [7] [8]. Creative crafting in groups can be used as an intervention to explore new ways of problem-solving and learning, both of which contribute to a woman's sense of control in life [9]-[11]. Nurses can play an important role in the development and implementation of creative interventions designed to counter the longer-term emotional and psychological consequences of trauma [12]. Creativity as a therapeutic endeavor can be a useful tool for nurses and is relatively easy and inexpensive to implement. Limited evidence exists, however, regarding the effectiveness of creative expression as a nursing intervention with trauma survivors. The purpose of this study was to explore how participation in a weekly craft group may influence anxiety, depression, self-esteem, and self-confidence among women who have experienced emotional and physical trauma.

\section{Background}

\subsection{Creative Expression Defined}

Webster's dictionary defines creativity as the ability to make new things or think of new ideas [13]. Others have described creativity as a process that requires individuals to be open to new ideas and possibilities [14]. Creative expression is a means by which new ideas, innovative solutions, or advanced problem-solving occur [15]. Regardless of the end product, creativity can be a powerful and useful force that supports the healing process [16]. Activities often described as creative and those that produce therapeutic health benefits include art, dance, music, drama, storytelling, painting, and various forms of writing [17].

\subsection{Health Benefits of Creative Expression and Crafting}

Connections between creativity, art, and health exist. Although randomized controlled trials are limited, there is a growing body of knowledge that suggests that engagement in artistic endeavors has significant health benefits [9] [18] [19]. Psychological benefits are attributed to increases in production of neurotransmitters and release of endorphins thought to occur as byproducts of the creative process [11]. Reductions in depression, negative emotions, anxiety, and stress have also been reported [7] [17] [20]. When used as a therapeutic intervention, creative activities influence perceptions about control in life, sense of purpose, confidence with self-expression, and development of social support systems [10] [16].

In this study, creative expression is synonymous with crafting. It differs from traditional art therapy in that its' purpose is not to uncover repressed memories or painful secrets associated with the traumatic experience. No specific training in the arts is required to be a successful crafter; the activities rely on basic skills available to everyone, not just the artistically gifted [19] [21]-[24].

While not considered a professional form of therapy, crafting can be therapeutic in that it produces a phenomenon known as "flow". First described by psychologist Mihaly Czikszentmihalyi, flow is that moment in time when you are so completely absorbed in an activity that nothing else seems to matter [25]. Crafting triggers the flow response [26]. The effects of flow are similar to those produced by meditation. Similarly, repetitive hand movements associated with crafting activities produce physiological changes commonly referred to as the relaxation response [27]. The effect, likened to that of meditation, yoga, or tai chi, brings about physical relaxation, relief from worrying thoughts, improvements in self-esteem, enhanced perceptions of control in life, and energizing thoughts [23].

Women who have experienced emotional and physical trauma benefit from reliable social support [28] [29]. Crafting groups offer opportunities for friendship, affirmation, and support [10] [30]. New relationships and patterns of communication emerge as participants experience a sense of being listened to, respected, and valued. Regular attendance can counter the social isolation and perceived loss of control so commonly experienced by women in abusive relationships [10] [31] [32]. 


\section{Purpose and Design}

The purpose of this study was to explore how participation in group crafting activities may influence anxiety, depression, stress, self-esteem, and self-confidence among women who have experienced emotional and physical trauma. A pre-post test design was used with a visual analog scale (VAS) as the method of measurement. Observation and field notes were used for qualitative data generation.

\subsection{Method}

University institutional review board approval was obtained. Participants were recruited from several agencies that provide services to women who have experienced trauma, including local domestic violence and homeless shelters and those that provide residential and nonresidential drug and alcohol treatment services. Participation was open to any adult woman over the age of 18 who had experienced emotional or physical trauma. A convenience sample of 37 women participated in the 7-week group intervention. Demographic data were not collected. A control group was not available.

Weekly group sessions were offered in a neighborhood church. Special consideration was given to the safety of the location to minimize the risks for women who were perhaps still involved with their abusive partner [33]. As part of a larger project, data collection for this study occurred in a 7-week period during the summer of 2013.

The researcher's role was to identify creative activities appropriate for each session, secure supplies and materials, and promote an environment that was safe and conducive to creativity. Throughout each session, the researcher observed the unfolding creative expressions, individual behaviors, and group interactions which provided a framework for facilitation and support of the group process. Participants were encouraged to share their thoughts and feelings spontaneously during the session, at the conclusion of the session, or both.

Visual analog scales (VAS) were used in this study as a measurement tool. Recognized for their simplicity and ease of administration, visual analog scales are widely used in social, behavioral, and clinical research [34] [35]. One significant advantage of the VAS is that the scales provide quantitative, interval-level data that is likely to be normally distributed with minimal bias [36] [37]. The VAS is also a common method used to gather quantifiable subjective ratings in a quick and simple way [38].

From a practical viewpoint, visual analogue scales allow the rater to place a single mark along a line somewhere between two perpendicular poles. The poles anchor the line at either end and represent the subjective phenomena to be measured. In many instances, the poles represent exact opposites of the subjective feelings or attitudes under investigation. For example, the poles of a VAS may ask about feelings related to depression in terms of "extremely depressed" as one of the poles versus "not depressed" at the other pole. The rater's mark coincides with their feeling or attitude about the subjective phenomena of interest. The line can be horizontal or vertical and is generally $100 \mathrm{~mm}$ in length [34] [39]. To maximize understandability, no intermediate marks, gradations, or terms should appear along the line between the poles [37] [39]. The completed VAS is scored by measuring the millimeters from the low end of the scale to the point where the rater's mark appears on the line. The VAS is appropriate for use with adults and children, with individuals who have limited or unknown literacy skills, and in situations where time and simplicity may influence completion [39]. In most instances, the VAS takes less than 5 minutes to complete.

In this study, the VAS was completed by each participant immediately before and after each group session to record their subjective sense of anxiety, depression, stress, self-esteem, and self-confidence. The visual analogue scales were horizontal and $100 \mathrm{~mm}$ in length. Participant observation and field notes were used to generate qualitative data.

\subsection{Procedure}

At the beginning of each session, participants were provided an explanation of the study. Written informed consent was obtained. The group met for 1.5 hours each week over a period of seven weeks. By design, participants were not asked to discuss their trauma history or describe their prior experiences with trauma or violence [7]. Introductions were by first name only.

An overview of the crafting activity was provided at the beginning of each session. As much as possible, a 
wide variety of supplies were provided for each activity. Examples of the crafting activities were provided in various and often incomplete formats to convey the message that there was more than one way to approach the project. Each week the researcher emphasized that previous art experience was not necessary and that there were no right or wrong outcomes associated with any of the crafting activities.

Crafting activities offered over the 7-week period included jewelry making, cross stitch, embellishment of colored bottles with glass beads, Coptic stitch binding, crochet, embellishment of flip flops, and mosaics. Each session offered two crafting activity choices. Participants were free to choose their preferred activity.

Each session concluded with closing comments by the researcher with an invitation to the next week's session. Participants were provided the opportunity to discuss their creative work if they felt led to do so. They were also encouraged to continue their work outside of the weekly group sessions if they preferred; "to go" supplies were made available accordingly.

\subsection{Data Analysis}

A clear PVC Visual Analog Scale ruler was used to score the participant's visual analogue scales. The ruler allowed for exact placement over the participant's VAS to ensure reliable measurement.

The distribution of VAS scores was evaluated prior to analysis using IBM SPSS Statistics 20 software [39]. Scores on the dependent variable were found to be reasonably normally distributed.

A paired sample $t$ test was used to evaluate the group crafting intervention. An increase in the VAS score indicated an increase in the variable being measured. Likewise, a decrease in the VAS score indicated a decrease in the associated variable being measured. An alpha level of 0.05 was used for all statistical tests. During the 7 -week series, 37 women participated in the group activities. Four of the women chose not to complete the pre and post intervention VAS instruments.

Observations and field notes informed several qualitative themes that emerged over the course of the 7-week series.

\subsection{Results}

Significant reductions were noted in the variables of anxiety, depression and stress after the intervention (Table 1). Participants also experienced significant increases in self-esteem and self-confidence. Cohen's d statistic [40], [41] indicated a large effect size for anxiety (0.72) and stress (0.69). Moderate effect size was determined for self-confidence (0.36), depression (0.41), and self-esteem (0.52) (Table 2).

Observations and field notes informed several qualitative themes that emerged over the course of the 7-week series.

- Soothing the Self-Of note is the observation that the process of creating art offered a self-soothing experience for participants. The stresses of life were often discussed among the women at the beginning of the sessions, but then faded from conversation. Observable behavior changes occurred in the form of relaxed body language, friendly conversations, audible laughing, and smiling faces. There were no imposed restrictions on conversation, yet the room was often free from noise as the participants worked quietly on their artistic endeavors. Several of the creative activities, such as the Coptic stitching and jewelry making, required concentration. During these sessions, participants mentioned that the need for concentration served as a distractor from their "real world" concerns, if only for an hour.

- Safe Space to Be-Participants noted that they felt safe within the physical space and appreciated the relaxed and "no pressure" environment. Socialization and development of new interpersonal skills was evident as participants experienced spontaneous and unscripted interactions with their peers. Mingling even after the session was over became common.

- Make One, Give One-Quite often participants would indicate at the conclusion of the group activity that their finished product was a gift for someone. If time allowed, women would make more than one craft item. This practice became known as "make one, give one." Participants who were residents of the local domestic violence shelter often made an extra craft piece to be used as a donated item for the shelter's annual fundraising auction.

- Spirituality and Faith-Of note is the observation that participants incorporated their personal symbols of spirituality or faith into their craft pieces. Integration of angels, crosses, and religious words occurred often. Christian and Native American influences were the most commonly used symbols. Several women 
Table 1. Means and standard deviations for dependent variables $(n=33)$.

\begin{tabular}{ccccc}
\hline \multirow{2}{*}{ Variables } & \multicolumn{2}{c}{ Pre-Intervention VAS Score } & \multicolumn{2}{c}{ Post Intervention VAS Score } \\
\cline { 2 - 5 } & Mean & Standard Deviation & Mean & Standard Deviation \\
\hline Anxiety & 51.75 & 24.43 & 34.44 & 19.30 \\
Depression & 41.50 & 27.62 & 30.44 & 21.42 \\
Stress & 55.78 & 25.00 & 38.00 & 21.85 \\
Self-Esteem & 52.53 & 22.34 & 66.44 & 18.85 \\
SelfConfidence & 58.00 & 25.42 & 68.94 & 18.06 \\
\hline
\end{tabular}

Table 2. Paired differences for dependent variables $(\mathrm{n}=33)$.

\begin{tabular}{ccccc}
\hline Variables & Mean Differences & Standard Deviation & $p$ Value & Cohen's d Effect Size \\
\hline Anxiety Pre/Post & 17.31 & 24.16 & $<0.001$ & 0.72 \\
Depression Pre/Post & $11 / 06$ & 27.23 & 0.028 & 0.41 \\
Stress Pre/Post & 17.78 & 25.83 & $<0.001$ & 0.69 \\
Self-Esteem Pre/Post & -13.91 & 26.35 & 0.005 & 0.52 \\
Self-Confidence Pre/Post & -10.04 & 30.26 & 0.049 & 0.36 \\
\hline
\end{tabular}

commented that their finished projects were in honor of a close friend or relative who had died or with whom they no longer had a relationship. One woman made a mosaic in honor of her young adult son who had died in a gang-related incident.

- Sense of Satisfaction, Accomplishment and Affirmation-Women who participated in the creative activities shared that they had limited or no prior experience with artistic endeavors. For some, their recollection of their experiences with creating art went back to their childhood years in grade school. They lamented that too many years had passed since they had experienced the creativity that comes so easily as a child. Many of the participants voiced approval of the notion that they were free to choose the way in which they created their art piece each week. Enthusiasm to create and willingness to engage in the weekly activities was evident by their repeated attendance and questions about the planned activities for the upcoming week.

\section{Discussion}

The purpose of this study was to explore how participation in group crafting activities may influence anxiety, depression, stress, self-esteem and self-confidence in women who have experienced emotional and physical trauma. Among the 33 women who participated in the study, the intervention was found to have a significant positive effect across all variables.

Engagement in creative expression offered participants the opportunity to express their emotions and feelings in a non-threatening way. There was no pressure to perform in a specific way nor to self-disclose or reveal the context of their trauma experience. Rather the focus was on using their creative energy in whatever way felt best in the moment. Consistent with findings from other studies, engagement in the crafting activities served as a temporary distractor from troubles and brought about relief from thoughts tied to the previous traumatic experience. Crafting was used successfully as an intervention to counter the effects of stress, much like guided imagery and meditation.

The format for the weekly craft group in this study was intended to offer reprieve and refuge from the toxic stressors that often linger and persist even after exposure to trauma has ended [7] [8]. Experiencing a safe place to be, for themselves and their children, had a positive impact on reducing anxiety and stress. As a result, participants were able to relax and appreciate the full benefit of the crafting experience, including the recognition that crafting can be a non-pharmacological intervention to soothe the self and a useful self-care tool in the management of anxiety and anger. Group members also benefited from the enhanced socialization and communica- 
tion processes inherent in the group format identified in similar studies [10] [31].

Intrinsic satisfaction and a positive sense of accomplishment are important aspects of psychological well-being [9]. Participants in the crafting groups experienced increases in self-esteem and self-confidence. Attention to the details of crafting and the completion of a project offered opportunities to experience satisfaction and affirm creative skills despite limited or nonexistent formal training in the arts. In addition, completed projects were often a means to express a wide range of emotions and served as symbolic expressions of grief, faith, and hope.

Fourteen children were provided childcare over the course of the 7-week crafting series. Intended to limit or eliminate barriers in attendance, provision of childcare was often mentioned by group participants as a much appreciated service. Because their children were cared for and having fun, mothers perceived their time each week as a personal respite without the expense or guilt associated with leaving the child with a babysitter. Trained childcare volunteers, safe and age-appropriate space, snacks and fun activities allowed participants to focus on their crafting activity without distraction or worry. Consistent with other published studies, provision of childcare influenced their decision to return for additional group sessions [29].

\subsection{Implications for Nursing}

Understanding the healing benefits that can be achieved through creative expression is an important aspect of the "art" of holistic nursing practice [15]. Whether through referral or provision of direct service, nurses should consider crafting as one form of creative expression that is an effective intervention to support continued healing for traumatized women long after traditional support services have ended.

Nurses in a variety of practice settings can serve in key leadership roles to initiate this type of group activity in their community and spearhead the organizational effort to ensure its success. Compared to other interventions, crafting activities are relatively inexpensive and easy to organize. Support in the form of physical space, supplies, and human resources are readily available in most communities. Inviting support from a variety of resources strengthens community connectedness and fosters the notion that a community cares about its women who have experienced trauma. Women in various stages of healing can benefit from knowing that their community supports their journey toward wellness.

\subsection{Study Limitations}

Several limitations are inherent in this study. Use of convenience sampling and small sample size limit its generalizability to larger populations of women who have experienced emotional and physical trauma. Self-report as a victim of trauma, accurate and honest responses on the visual analog scales, and the authenticity of anecdotal comments are additional limitations.

Horizontal visual analogue scales were used in this study. Gift [39] cautions that participants tend to mark all of the scales down the middle when arranged horizontally on the instrument. Perhaps the layout of the instrument itself should be considered a limitation. In addition, because the visual analog scales were used in a repeated measures design, the possibility exists that the score changes were due to the participant's experience and familiarity with the instrument [35].

\subsection{Areas for Further Study}

Future research is necessary to better understand how creative expression can impact the lives of women who have experienced emotional and physical trauma. Additional studies with a larger sample size are needed to determine if certain crafting activities are more or less effective than others. Similarly, are the benefits derived from the crafting experience sustained or short term? Efforts to quantify the physiological benefits, if any, of the crafting group experience is another area warranting further investigation.

While it was common for the participants in this study to make anecdotal comments about the perceived benefits of creative expression, a more detailed explanation from the participant's perspective could be useful in understanding how the benefit is derived. For example, is the participant's perceived benefit associated with the group experience, the specific crafting activity, or both? Exploring this aspect of the experience would be helpful in planning future activities.

There are few written accounts of creative art activities being used as nursing interventions. In an era dominated by evidence-based practice, it is important for nurses to pursue a greater understanding of the art of nurs- 
ing and the important contribution of creativity when used as a nursing intervention. Long overdue is the acknowledgement that nurses should integrate aspects of creativity into their practice.

\section{Acknowledgements}

Funding was received from the Episcopal Church, Diocese of Missouri in the form of a competitive grant to purchase supplies for the weekly group sessions. The researcher did not receive any stipend or salary.

\section{References}

[1] Woods, S.J. and Gill, J. (2011) Family Violence: Long-Term Health Consequences of Trauma. In: Humphreys, J. and Campbell, J.C., Eds., Family Violence and Nursing Practice, 2nd Edition, Springer Publishing Company, New York, 29-50.

[2] Ham-Rowbottom, K.A., Gordon, E.E., Jarvis, K.L. and Novaco, R.W. (2005) Life Constraints and Psychological Well-Being of Domestic Violence Shelter Graduates. Journal of Family Violence, 20, 3174-3177. http://dx.doi.org/10.1007/s10896-005-3174-7

[3] Pico-Alfonso, M., Garcia-Linares, M., Celda-Navarro, N., Blasco-Ros, C., Echeburua, E. and Martinez, M. (2006) The Impact of Physical, Psychological, and Sexual Intimate Male Partner Violence on Women's Mental Health: Depressive Symptoms, Posttraumatic Stress Disorder, State Anxiety, and Suicide. Journal of Women's Health, 15, 599-611. http://dx.doi.org/10.1089/jwh.2006.15.599

[4] Cohen, B., Barnes, M. and Rankin, A. (1995) Managing Traumatic Stress through Art: Drawing from the Center. The Sidran Press, Baltimore.

[5] Flood, M. and Phillips, K. (2007) Creativity in Older Adults: A Plethora of Possibilities. Issues in Mental Health Nursing, 28, 389-411. http://dx.doi.org/10.1080/01612840701252956

[6] Wilson, J. (2014) This Is Your Brain on Knitting. http://www.cnn.com/2014/03/25/health/brain-crafting-benefits

[7] Allen, K. and Wozniak, D. (2011) The Language of Healing: Women's Voices in Healing and Recovering from Domestic Violence. Social Work in Mental Health, 9, 37-55. http://dx.doi.org/10.1080/15332985.2010.494540

[8] Anderson, L. and Gold, K. (1998) Creative Connections: The Healing Power of Women’s Art and Craft Work. Women \& Therapy, 21, 15-36. http://dx.doi.org/10.1300/J015v21n04_02

[9] Creek, J. (2008) Occupational Therapy and Mental Health. 4th Edition, Elsevier, New York.

[10] Griffiths, S. (2008) The Experience of Creative Activity as a Treatment Medium. Journal of Mental Health, 17, 49-63. http://dx.doi.org/10.1080/09638230701506242

[11] Lane, M.R. (2006) Arts in Health Care: A New Paradigm for Holistic Nursing Practice. Journal of Holistic Nursing, 24, 70-75. http://dx.doi.org/10.1177/0898010105282465

[12] Crenshaw, D. (2006) Neuroscience and Trauma Treatment: Implications for Creative Arts Therapists. In: Carey, L., Ed., Expressive and Creative Arts Methods for Trauma Survivors, Jessica Kingsley Publishers, London, 21-38.

[13] Creativity (n.d.) In Merriam-Webster Online. http://www.merriam-webster.com/dictionary/citation

[14] Fisher, B. and Specht, D. (1999) Successful Aging and Creativity Later in Life. Journal of Aging Studies, 13, 457-472. http://dx.doi.org/10.1016/S0890-4065(99)00021-3

[15] Fasnacht, P. (2003) Creativity: A Refinement of the Concept for Nursing Practice. Journal of Advanced Nursing, 42, 195-202. http://dx.doi.org/10.1046/j.1365-2648.2003.02516.x

[16] Perruzza, N. and Kinsella, E.A. (2010) Creative Arts Occupations in Therapeutic Practice: A Review of the Literature. British Journal of Occupational Therapy, 73, 261-268. http://dx.doi.org/10.4276/030802210X12759925468943

[17] Stuckey, H.L. and Nobel, J. (2010) The Connection between Art, Healing, and Public Health: A Review of Current Literature. American Journal of Public Health, 100, 254-263. http://dx.doi.org/10.2105/AJPH.2008.156497

[18] Kelly, C.G., Cudney, S. and Weinert, C. (2014) Use of Creative Arts as a Complementary Therapy by Rural Women Coping with Chronic Illness. Journal of Holistic Nursing, 30, 48-54. http://dx.doi.org/10.1177/0898010111423418

[19] Reynolds, F. and Prior, S. (2006) Creative Adventures and Flow in Art-Making: A Qualitative Study of Women Living with Cancer. British Journal of Occupational Therapy, 69, 255-262.

[20] Walsh, S.M., Martin, S.C. and Schmidt, L.A. (2004) Testing the Efficacy of a Creative-Arts Intervention with Family Caregivers of Patients with Cancer. Journal of Nursing Scholarship, 36, 214-219.

http://dx.doi.org/10.1111/j.1547-5069.2004.04040.x

[21] Liebmann, M. (1986) Art Therapy for Groups: A Handbook of Themes, Games and Exercises. Brookline Books, Brookline. 
[22] McGarry, T.J. and Prince, M. (1998) Implementation of Groups for Creative Expression in a Psychiatric Inpatient Unit. Journal of Psychosocial Nursing and Mental Health Services, 36, 19-24.

[23] Reynolds, F. (2000) Managing Depression through Needlecraft Creative Activities: A Qualitative Study. The Arts in Psychotherapy, 27, 104-114. http://dx.doi.org/10.1016/S0197-4556(99)00033-7

[24] Weston, A. (2007) Creativity for Critical Thinkers. Oxford University Press, Oxford.

[25] Csikszentmihalyi, M. (1990) Flow: The Psychology of Optimal Experience. Harper and Row, New York.

[26] Gutman, S.A. and Schindler, V.P. (2007) The Neurological Basis of Occupation. Occupational Therapy International, 14, 71-85. http://dx.doi.org/10.1002/oti.225

[27] Benson, H. and Klipper, M.Z. (2000) The Relaxation Response. HarperCollins, New York.

[28] Buschel, B. and Madsen, L. (2006) Strengthening Connections between Mothers and Children. Journal of Aggression, Maltreatment \& Trauma, 13, 87-108. http://dx.doi.org/10.1300/J146v13n01_05

[29] Letourneau, N., Morris, C., Stewart, M., Hughes, J., Critchley, K. and Secco, L. (2013) Social Support Needs Identified by Mothers Affected by Intimate Partner Violence. Journal of Interpersonal Violence, 28, 2873-2893. http://dx.doi.org/10.1177/0886260513488685

[30] Leckey, J. (2011) The Therapeutic Effectiveness of Creative Activities on Mental Well-Being: A Systematic Review of the Literature. Journal of Psychiatric and Mental Health Nursing, 18, 501-509. http://dx.doi.org/10.1111/j.1365-2850.2011.01693.x

[31] Larance, L.Y. and Porter, M.L. (2004) Observations from Practice: Support Group Membership as a Process of Social Capital Formation among Female Survivors of Domestic Violence. Journal of Interpersonal Violence, 19, 676-690. http://dx.doi.org/10.1177/0886260504263875

[32] Gillam, T. (2013) Creativity and Mental Health Care. Mental Health Practice, 16, 24-30. http://dx.doi.org/10.7748/mhp2013.06.16.9.24.e807

[33] Sullivan, C. and Cain, D. (2004) Ethical and Safety Considerations When Obtaining Information from or about Battered Women for Research Purposes. Journal of Interpersonal Violence, 19, 603-618. http://dx.doi.org/10.1177/0886260504263249

[34] Foley, D. (2008) Development of a Visual Analogue Scale to Measure Curriculum Outcomes. Journal of Nursing Education, 47, 209-213. http://dx.doi.org/10.3928/01484834-20080501-04

[35] Wewers, M.E. and Lowe, N.K. (1990) A Critical Review of Visual Analogue Scales in the Measurement of Clinical Phenomena. Research in Nursing \& Health, 13, 227-236. http://dx.doi.org/10.1002/nur.4770130405

[36] Lee, K.A. and Kieckhefer, G.M. (1989) Measuring Human Responses Using Visual Analogue Scales. Western Journal of Nursing Research, 11, 128-132. http://dx.doi.org/10.1177/019394598901100111

[37] Cline, M.E., Herman, J., Shaw, E.R. and Morton, R.D. (1992) Standardization of the Visual Analogue Scale. Nursing Research, 41, 378-379. http://dx.doi.org/10.1097/00006199-199211000-00013

[38] Marsh-Richard, D., Hatzis, E., Mathias, C., Venditti, N. and Dougherty, D. (2009) Adaptive Visual Analog Scales (AVAS): A Modifiable Software Program for the Creation, Administration, and Scoring of Visual Analog Scales. Behavioral Research Methods, 41, 99-106. http://dx.doi.org/10.3758/BRM.41.1.99

[39] Gift, A. (1989) Visual Analogue Scales: Measurement of Subjective Phenomena. Nursing Research, 38, 286-288. http://dx.doi.org/10.1097/00006199-198909000-00006

[40] Cohen, J. (1988) Statistical Power Analysis for the Behavioral Sciences. 2nd Edition, Lawrence, Erlbaum Associates, Hillsdale.

[41] Cohen, J. (1992) A Power Primer. Psychological Bulletin, 112, 155-159.

http://dx.doi.org/10.1037/0033-2909.112.1.155 
Scientific Research Publishing (SCIRP) is one of the largest Open Access journal publishers. It is currently publishing more than 200 open access, online, peer-reviewed journals covering a wide range of academic disciplines. SCIRP serves the worldwide academic communities and contributes to the progress and application of science with its publication.

Other selected journals from SCIRP are listed as below. Submit your manuscript to us via either submit@scirp.org or Online Submission Portal.
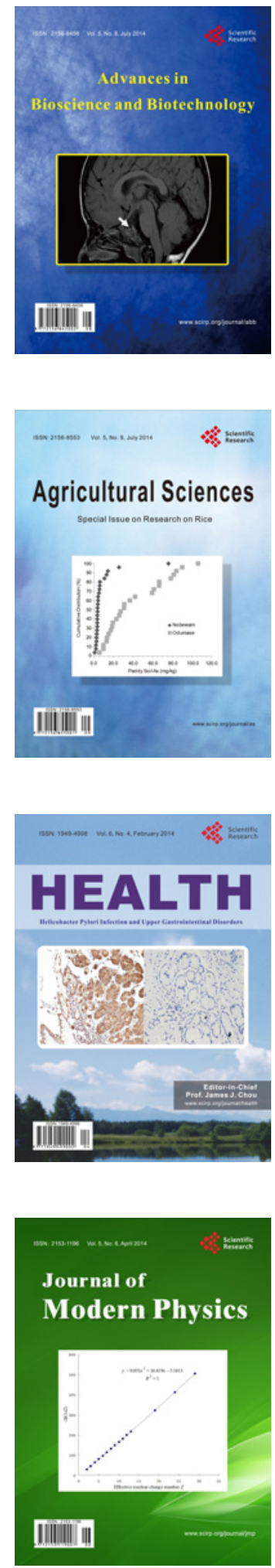
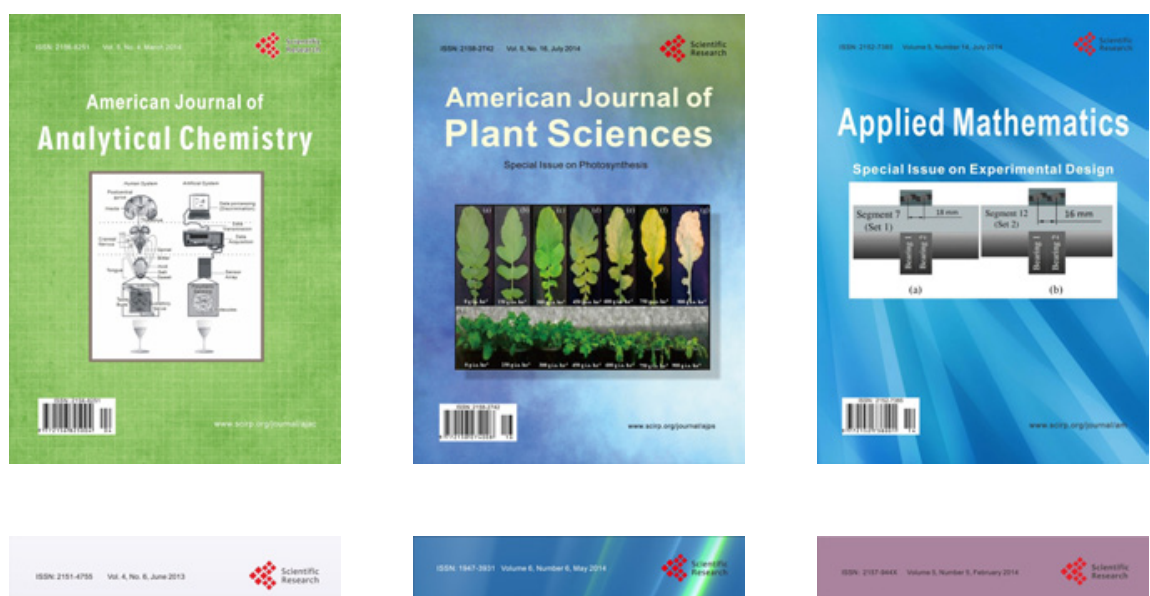

Creative Education
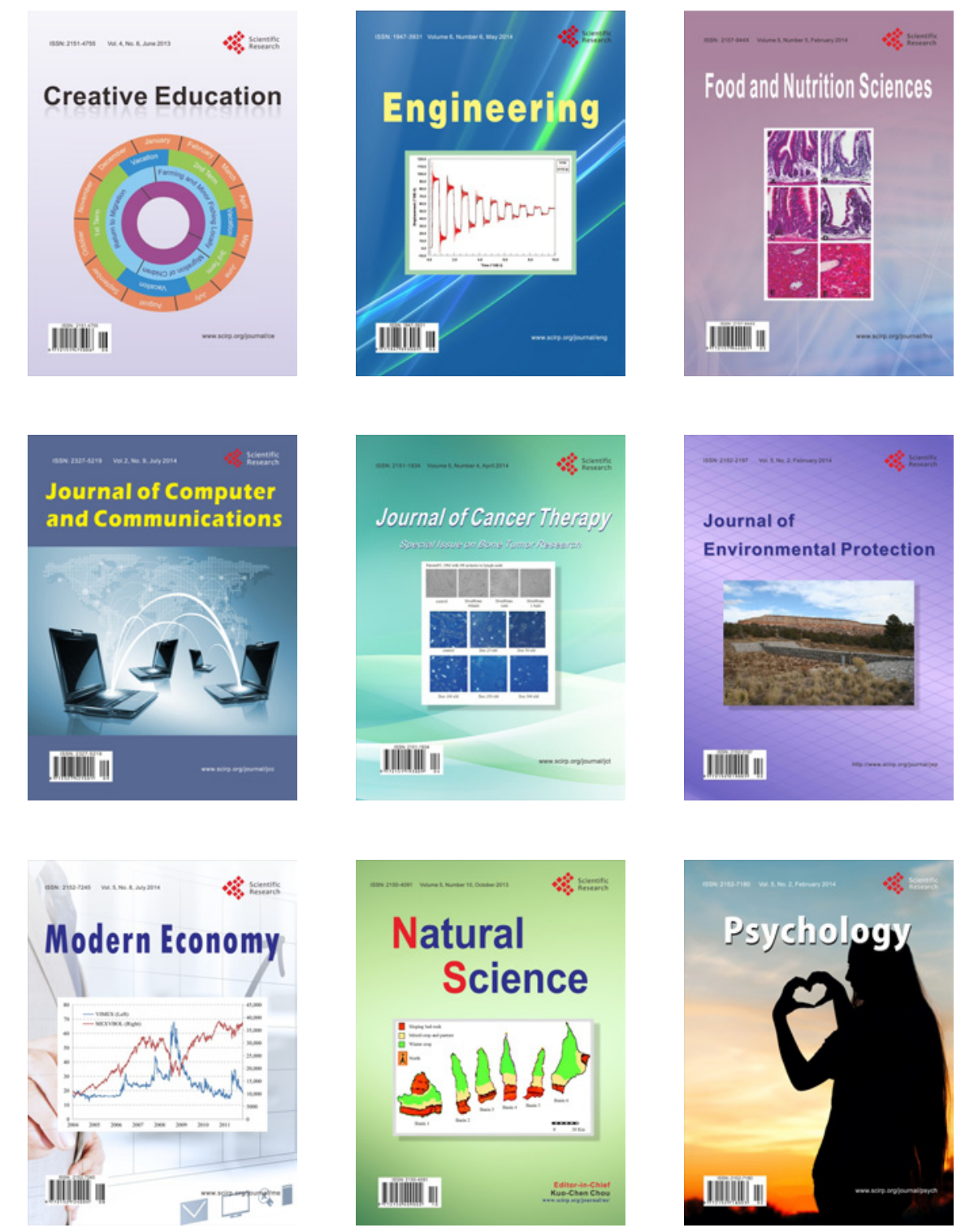